\title{
Use of High Pressure Freezing and Freeze Substitution to Study Host- Pathogen Interactions in Fungal Diseases of Plants
}

\author{
C. W. Mims,* and E. A. Richardson** \\ *Department of Plant Pathology, University of Georgia, Athens, GA 30602 \\ **Department of Botany, University of Georgia, Athens, GA 30602
}

The value of high pressure freezing followed by freeze substitution (HPF/FS) for ultrastructural studies of host-pathogen interactions in fungal diseases of plants was first demonstrated in rust infections by Knauf et al. [1] Encouraged by these results, we began to explore the use of HPF/FS for the study of host-pathogen interactions in a variety of different types of plant diseases caused by biotrophic fungi. Here we discuss some of our results. Emphasis is placed upon the ultrastructure of haustoria and details of the haustorium-host cell interface.

Infected leaf samples approximately $1-\mathrm{mm}^{2}$ were placed in either brass or aluminum planchettes along with a drop of cryoprotectant (15\% dextran in water) and frozen using a Balzers 010 high pressure freezing machine. Frozen samples were transferred to liquid nitrogen and then to a substitution fluid consisting of $2 \% \mathrm{OsO}_{4}$ in anhydrous acetone containing $0.05 \%$ uranyl acetate. Samples were substituted according to the procedures of Hoch [2] and then processed for study with transmission electron microscopy following the procedures of Mims et al. [3]

In the four host-pathogen systems discussed here we obtained many well-preserved host cells and fungal haustoria. Haustoria of Exobasidium vaccinii (Fig. 1), a parasite of Rhododendron, consisted of short, lobed branches that extended only a short distance into host cells. Each lobe possessed an electron dense cap-like structure and contained conspicuous branched, membranous inclusions. The haustoria of Puccinia hemerocallis (Fig. 2) and Frommeëla mexicana var. indicae (Fig. 3), two rust fungi we studied, were similar to those of other rust fungi. [1] Each possessed a slender neck region and an expanded body separated from the host cell cytoplasm by an apoplastic extrahaustorial matrix and an extrahaustorial membrane continuous with the host cell plasma membrane. The extrahaustorial membrane was well-preserved in cryofixed samples and exhibited a smooth profile (Fig.4). This membrane was continuous with tubular elements that extended into the host cell cytoplasm (Fig. 2). In P. hemerocallis many of these elements were beaded in appearance while others were connected to flattened cisternae that bore short beaded chains (Fig. 5). In powdery mildew of poinsettia, haustoria were produced only in leaf epidermal cells. Each haustorium consisted of a long slender neck and an expanded body with numerous finger-like branches (Fig. 6). Haustoria were separated from the host cell cytoplasm by an extrahaustorial matrix and an extrahaustorial membrane, portions of which were highly convoluted.

\section{References}

[1] G.M. Knauft et al., Physiol. Mol. Plant Path. 34 (1989) 519.

[2] H.C. Hoch, in Ultrastructure Techniques for Microorganisms, Eds. H. C. Aldrich and W. T.

Todd, New York: Plenum (1986) 183.

[3] C.W. Mims, Can. J. Bot. 79 (2001) 383. 


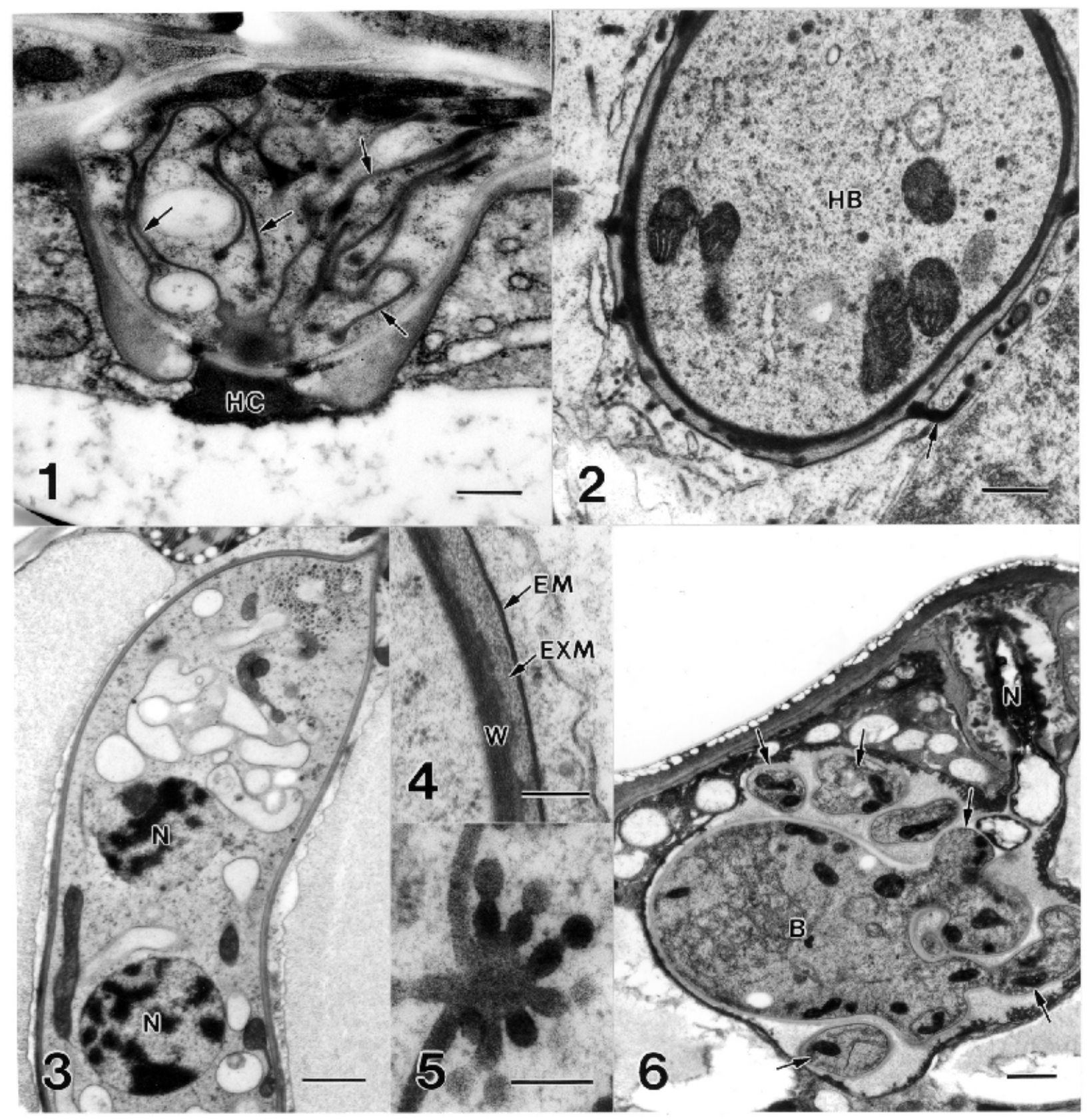

FIG. 1. Haustorium of Exobasidiun vaccinii. Note the haustorial cap (HC) and the distinctive membranous inclusions (arrows) present in the haustorium cytoplasm. Bar: $0.3 \mu \mathrm{m}$.

FIG. 2. Cross section of a haustorial body (HB)of Puccinia hemerocallis in a daylily leaf cell. Note the tubular element (arrow) protruding into the host cell cytoplasm. Bar: $0.3 \mu \mathrm{m}$.

FIG. 3. Longitudinal section of part of a haustorial body of Frommeëla mexicana var. indicae in a leaf cell of Indian strawberry. The nuclei of the haustorium are visible at N. Bar: $1 \mu \mathrm{m}$. FIG. 4. The host-cell interface between $P$. hemerocallis and a daylily cell. The haustorial wall (W), extrahaustorial matrix (EXM) and extrahaustorial membrane (EM) are visible. Bar: 0.15 $\mu \mathrm{m}$.

FIG. 5. A flattened cisterna bearing beaded chains in an infected daylily cell. Bar: $0.3 \mu \mathrm{m}$. FIG. 6. Haustorium of Oidium sp. in an epidermal cell of a poinsettia leaf. Note the neck (N), body (B) and finger-like branches (arrows) that comprise the haustorium. Bar: $0.3 \mu \mathrm{m}$. 